\title{
La carpintería de armar en el antiguo Palacio Real de León
}

Joaquín García Nistal

RESUMEN. El Palacio Real de León, hoy desaparecido, fue uno de los edificios más importantes de la arquitectura civil medieval de la ciudad. En este trabajo estudiamos cuatro de sus armaduras de madera a través de nuevos documentos gráficos e históricos. Esperamos así contribuir al conocimiento de este interesante capítulo de la Historia capitalina.

Palabras clave: Palacio Real de León, carpintería de armar, carpintería de lo blanco, mudéjar.

ABSTRACT. The Royal Palace of Leon, today disappeared, was one of the most important buildings of the medieval civil architecture of the city. In this work we study four of its wooden ceilings through new graphic and historical documents. We hope it helps to improve the knowledge about this interesting chapter of the Leon's History.

Key words: Royal Palace of León, Wooden ceiling, mudejar.

\section{EL PALACIO REAL DE LEÓN. BRE- VE RESEÑA HISTÓRICA.}

En 1350 se alzaba rey de la Corona de Castilla Pedro I (1350-1369). Dos años después de estos acontecimientos, en 1352, su hermano Don Enrique, conde de Trastámara, iniciaba una sacudida de sublevaciones contra el anterior monarca con el fín de obtener el título real. Se daba comienzo, de este modo, a una guerra civil que provocó la división de la nobleza española.

Mediado el mes de enero de 1368, D. Enrique, tras la toma de la villa de Dueñas, llegaba a León -ciudad que desde los inicios de la contienda había apoyado fervientemente al rey D. Pedro I- con afán de apoderarse de la urbe. Los leoneses resistieron la incursión de las tropas del conde Enrique hasta el 30 de abril de $1368^{1}$.

Un año más tarde, muerto Pedro I, Enrique II se proclamaba rey e instauraba la dinastía Trastámara en la Corona de Casti1la. A partir de este momento, el nuevo monarca buscó ganarse el beneplácito de los leoneses a través de la concesión de múltiples privilegios para la ciudad. Esta

${ }^{1}$ P. LÓPEZ DE AyALA, Colección de las crónicas y memorias de los reyes de Castilla. D. Pedro I, D. Enrique II, D. Juan I, D. Enrique III, tomo I, Madrid, 1779, pp. 520-521; M. RISCO, Historia de la ciudad y corte de León, y de sus reyes, Madrid, 1792, ed. facsímil, León, 1978, pp. 103104. Sobre el conflicto entre Pedro I y Enrique de Trastámara: J. CATALINA GARCíA, Castilla y León durante los reinados de Pedro I, Enrique II, Juan I y Enrique III, en Historia General de España, tomo XXXVIII, Madrid, 1892. 
misma razón debió impulsar, al rey Trastámara, a encargar la construcción de su alcázar en León hacia 1375 ó 1376. Al parecer, en 1377, los espacios palatinos regios ya se habían concluido, tal y como lo indicaba una inscripción, hoy desaparecida, ubicada en unos azulejos de la entrada al salón principal del recinto regio medieval ${ }^{2}$.

Este recinto palaciego erigido por Enrique II en León era un edificio de enormes dimensiones que ocupaba un notable solar entre la calle de la Rúa y la llamada "cerca nueva", extramuros del antiguo recinto amurallado y en un nuevo espacio de la ciudad que comenzaba a destacar como centro de la actividad comercial y lugar de residencia de las principales familias nobles.

Por sus características formales y arquitectónicas el conjunto aúlico respondía a los esquemas artísticos del siglo XIV hispano, donde la tradición medieval cristiana se fusiona con elementos islámicos.

El Palacio Real fue, tempranamente, víctima de diferentes usos, lo que determinó una paulatina desaparición de sus estructuras y elementos medievales. Así, el 22 de abril de 1528, Carlos I, mediante una Cédula Real, informado del mal estado de conservación del recinto real leonés $\mathrm{y}$, a petición de la ciudad, destinaba este dominio para albergar la casa del corregidor y la

\footnotetext{
${ }^{2}$ La trascripción de la misma la conocemos gracias a la obra de Risco: "ESTOS PALACIOS MANDÓ HACER EL MUY ALTO Y MUY NOBLE Y MUY PODEROSO SEÑOR DON ENRIQUE, QUE DIOS MANTENGA. ACABÁRONSE EN LA ERA DE MIL Y QUATROCIENTOS Y QUINCE AÑOS"; M. RISCO, España Sagrada, tomo XXXVI, Madrid, 1787, p. 38. A este mismo epígrafe alude Rada y Delgado afirmando que ya estaba desaparecido en 1870; J. D. RADA Y Delgado, "Arco del Antiguo Palacio de los Reyes, y fragmento de otro que perteneció al de los condes de Luna en León", Museo Español de Antigüedades, tomo II, Madrid, 1873, p. 517.
}

cárcel de la ciudad; obras que no concluyeron hasta $1568^{3}$.

Igualmente, en 1588, consta que, en este mismo lugar, tenía su sede el Archivo Municipal de la ciudad y, en 1693, el Palacio Real se utilizaba como vivienda para los señores corregidores de la ciudad, teniendo "dos salas de la audiencia, de ciudad y adelantamiento, el pósito y londiga, y la cárcel" ${ }^{\prime 4}$.

Sus últimos usos fueron destinados a cuartel y fábrica de tejidos, incendiada en los años de la guerra de la independencia ${ }^{5}$.

El 6 de junio de 1882, en un suelto del periódico leonés "La legalidad" se informaba: "me alegro que se esté derribando ya la cárcel vieja..." ${ }^{6}$. En el mismo periódico, el 20 de junio, ya se anuncia que "pronto se va a terminar el derribo de la cárcel vieja, quedando en la calle de la Rúa un magnífico solar que puede servir para abrir otra espaciosa avenida que salga a la carretera frente a la Puerta de la Reina" ${ }^{\prime 7}$.

Después de la descripción de este breve panorama histórico del antiguo Palacio Real de León, nuestra intención se fundamenta en reconstruir, en la medida de lo posible, los elementos arquitectónicos que configuraron el primitivo conjunto aúlico medieval, del que apenas han sobrevivido algunos restos. Entre ellos, en esta ocasión nos centraremos en la riqueza de las cubier-

\footnotetext{
3 J. D. RADA Y DELGADO, Op. cit., pp. 517-518

${ }^{4}$ F. CABEZA DE VACA QUIÑONES Y GUZMÁN, Resumen de las políticas Ceremonias con que se gobierna la noble, leal y antigua ciudad de León, cabeza de su gobierno, 1693, 3ae ed. León, 1889, pp. 28-30.

${ }^{5}$ M. BRAvo GuARIDA, "El cuartel de la fábrica", Vida leonesa, nํ57, León, 1924; M. BRAVO GUARIDA, “El cuartel de la fábrica", Rincones Leoneses, León, 1979, p. 72.

${ }^{6}$ M. Bravo Guarida, Op. cit., p. 72.

${ }^{7}$ Biblioteca Pública de León (B. P. L.), La legalidad. Periódico conservador, $\mathrm{n}^{\circ}$ 6, año I, martes 20 de junio de 1882. Citado en M. Bravo GUARIDA, Op. cit., p. 72.
} 
tas de madera que engalanaban este complejo arquitectónico.

A través de ellas intentaremos una aproximación a la realidad artística de un edificio, ya desaparecido, pero que jugó un papel primordial en la historia de la arquitectura leonesa del siglo XIV.

\section{DATOS SOBRE LOS ARTESONA- DOS DEL ANTIGUO PALACIO RE- AL LEONÉS.}

Cuál era el número total de armaduras que existían en las dependencias del Palacio Real de León, cuál era su ubicación dentro del mismo y cuántas de ellas aún se conservaban, fue uno de los retos que nos planteamos desde el inicio de esta investigación. Para esta tarea se hizo imprescindible recurrir, no sólo a las fuentes documentales y bibliográficas, sino también al material gráfico que hemos podido recoger. La parquedad y escasez de las referencias descriptivas a cerca del desaparecido Palacio Real leonés hacía, si cabe, más ardua la labor que deseábamos desempeñar.

La primera de las noticias que hace alusión a los "artesonados" del edificio aúlico procede de Juan de Dios de la Rada y Delgado quien, en 1873, elogiaba el edificio por tratarse de "un suntuoso palacio que, a juzgar por los escasos restos que de él nos han llegado hasta nosotros, debía ser digno rival del célebre Alcázar de D. Pedro, de Sevilla..." ${ }^{8}$. Del mismo modo, atestigua que observó, en 1870, "en una de las grandes salas que aún subsisten, si bien en camino de rápida destrucción, preciosísimo techo pintado de estilo mudéjar en su mejor periodo" ${ }^{\prime \prime}$.

La siguiente fuente relativa al estado de estas armaduras nos llevaba hasta la

\footnotetext{
${ }^{8}$ J. D. RADA Y DELGADO, Op. cit., pp. 513-514.

${ }^{9}$ Ibidem, idem.
}

Comisión de Monumentos de León. En el inventario de la misma, con fecha 2 de noviembre de 1885 , se dice que, estando "reunidos los señores que al margen se expresan en el salón de la Biblioteca Provincial, bajo la presidencia del señor D. Demetrio de los Ríos... diose lectura a dos importantes comunicaciones: la primera del señor gobernador militar de la provincia, trasladando una real orden por la que se concede a la comisión, bajo ciertas condiciones, los techos mudéjares del cuartel de la ciudad..." ${ }^{10}$.

Siguiendo este recorrido diacrónico, López de Castillón, en 1889, hace referencia a una de las techumbres del Palacio Real de León que, según sus propias palabras, "era riquísimo techo de madera de estilo mudéjar, pintado y dorado con el mejor gusto, correspondiente a un gran salón, y se hallaba en inminente ruina"11.

En 1924, según el estudio de Miguel Bravo Guarida, los restos reseñados por Rada habían desaparecido de su primigenio emplazamiento, por lo que, probablemente, habían sido destinados al depósito de Comisión de Monumentos, tal como se hacía mención en 1885. Pero Bravo describe otra de las techumbres que aún pervivían a mediados de la segunda década del siglo XX. Se trataba de otra armadura, gemela de la del gran salón ya aludido, “...actualmente solo queda a la vista una gran chimenea, algunos arcos de ladrillos,... el techo de madera en la escalera del fondo del patio,

${ }^{10}$ Biblioteca Publica de León (B. P. L.), Inventario de la Comisión de Monumentos de León, expedientes e informes, no 615, p. 26.

${ }^{11}$ F. CABEZA DE VACA QUIÑONES Y GUZMÁN, $O p$. cit., anotaciones de López de Castrillón, pp. 28-30. Parece que López de Castrillón, en su descripción a cerca de la cubierta de la gran sala anexa al patio, hace uso de las palabras de Rada y Delgado. 
que conserva la preciosa armadura mudéjar de lacería, medio encalada"12.

A través de este artículo tuvimos conocimiento de una nueva cubierta y su emplazamiento en la caja de una escalera sita al fondo del patio. Las fotografías de una armadura procedente del Palacio Real, halladas en el Archivo Histórico Municipal de León, así como los datos de su emplazamiento en la caja de una escalera no dejaban lugar a dudas, se trataba del mismo ejemplo que cita Bravo (lám. I) ${ }^{13}$.

Llegados a este punto de la investigación, documentamos la existencia y ubicación de dos techumbres de madera dentro del Palacio Real. La cubierta de un gran salón anejo al patio central, descrita por Rada y López de Castrillón, que pudo ser trasladada junto a otras armaduras a la Comisión de Monumentos hacia 1885. Igualmente teníamos constancia de otra techumbre perteneciente a una escalera localizada al fondo del patio ${ }^{14}$. La noticia de la similitud entre las mismas -se dice de ellas que eran gemelas- permite además confirmar que ambas responden a un mismo sistema de trabajo estructural y ornamental.

Otra de las indicaciones sobre las armaduras del Palacio parte de otro informe del presidente de la Comisión de Monumentos Históricos y Artísticos dirigido al alcalde de León el 20 de noviembre de 1944. En el mismo se notifica la posibilidad de la proyección y apertura de la calle de la Independencia y se añade que en el viejo

\footnotetext{
${ }^{12}$ M. Bravo Guarida, Op. cit., pp. 68-74.

${ }^{13}$ Archivo Histórico Municipal de León (AHML), Secretaría, Obras municipales, expte. № 4, 1994. Fui informado del depósito de estas fotografías por el Dr. D. Alejandro Valderas Alonso, a quien expreso desde aquí mi gratitud por la noticia.

${ }^{14}$ El acceso al palacio estaba situado en el lado oriental del complejo, de modo que esta escalera estaría ubicada a poniente.
}

cuartel de la Fábrica sólo quedan, como restos valiosos, pequeños fragmentos de un viejo artesonado que se deben llevar al museo provincial. Afortunadamente tales piezas sí hemos podido documentarlas gráficamente (lám. II) ${ }^{15}$. En la misiva del alcalde de León se advierte que el espacio del viejo palacio será utilizado para ubicar el Gobierno Militar y sus dependencias anexas, edificios para el servicio de intendencia y casas militares. Además de estos restos de armaduras, que a la sazón serán los trasladados al Museo Provincial de León, se afirma que existe "un artesonado... en la caja de la escalera del ángulo sur-oeste del cuartel, se halla en completa ruina, faltando gran número de tableros y carcomidos los que quedan, siendo de lamentar que a su tiempo no haya sido trasladado a un Museo siguiendo el camino de cuantos restos del antiguo palacio fueron apareciendo". Se deduce seguidamente que "el artesonado de lacería debe ser trasladado al Museo Provincial, si se pretende conservar lo que de él queda" ${ }^{16}$.

Obtenemos una nueva información que certifica la existencia, aún en 1944, de la techumbre emplazada en el ángulo suroeste del cuartel y que cubría la caja de la escalera (lám. I). Cubierta que pudo derrumbarse, pues desconocemos el paradero de sus restos. Los dos fragmentos, salva-

\footnotetext{
-

${ }^{15}$ Archivo de la Comandancia de Obras de Valladolid. Las fotografías pertenecen a las fechas de los derribos dentro del antiguo Palacio Real hacia 1944. En las mismas, pueden apreciarse las armaduras de madera, que hoy pertenecen al Museo Provincial, y que aún se mantenían en pié aunque afectadas notablemente. Agradezco a los profesores M ${ }^{a}$ Dolores Campos Sánchez-Bordona (Universidad de León) y Javier Pérez Gil (Universidad de Valladolid) la facilitación de esta documentación y su ayuda y consejos acerca del Palacio Real leonés, del que han realizado una monografía en vías de publicación.

16 AHML, Secretaría, obras municipales, expte. Cerca del arrabal de León, no 4, 1994. Deseo expresar nuevamente $\mathrm{mi}$ gratitud a D. Alejandro Valderas Alonso por la información sobre este documento.
} 
guardados en el Museo de León, no se corresponden con los documentos gráficos de la armadura de la escalera. Sin embargo, son las mismas piezas, ya fragmentarias, que se observan en las fotografías del Archivo de la Comandancia de Obras de Valladolid y probablemente las mismas a las que alude el informe de 1944 cuando menciona la existencia de pequeños fragmentos de un viejo artesonado (lám. II) ${ }^{17}$.

En los cuatro años que transcurren desde la fecha de este informe hasta la noticia publicada por Luengo, en su artículo de la Sociedad Española de Excursiones en 1948, se derruyeron los escasos restos del Palacio, como puede extraerse de la información que este último nos aporta. Afirma del palacio que "de su grandeza sólo quedan leves despojos... y posteriormente, allí (Museo Arqueológico Provincial) fueron a parar los notables artesonados que descubrió el señor Bravo, al ser derribada hace poco la última parte que del palacio resta$\mathrm{ba}^{\prime 18}$.

Por último, cabe añadir las noticias de Domínguez Berrueta, quien, en su estudio publicado en 1953, asevera que "del último palacio real construido en 1377 por Enrique II en la calle de la Rúa, el viejo ca-

\footnotetext{
${ }^{17}$ Estos dos fragmentos, custodiados en el Museo de León, pertenecen a dos cubiertas diferentes. No podemos aventurar cuál era su ubicación dentro del palacio, ni tenemos los suficientes datos para estimar si la mayor de estas piezas se correspondería con la que Rada describió en 1873. Sin embargo, esta hipótesis parece poco probable teniendo en cuenta que, Miguel Bravo, en 1924, momento en el que aún permanecen estos dos fragmentos dentro del Palacio Real, no observa la cubierta de la gran sala descrita anteriormente por Rada.

18 J. M. LUENGO, "Notas sobre lo "morisco" en la arquitectura civil de la provincia de León", Boletín de la Sociedad Española de Excursiones, Tomo LII, Madrid, 1948 , p. 5. Luengo interpreta que los restos de armaduras depositados en el Museo de León son los mismos que Bravo encontró en la caja de la escalera. Interpretación equívoca según hemos puesto de manifiesto.
}

mino francés de peregrinos, no queda allí absolutamente nada que lo recuerde" ${ }^{\prime 19}$.

Ahora bien, si en 1948, fecha en la que Luengo publica su artículo, los restos de "artesonados" del Palacio Real ya se habían llevado al Museo de León, parece lógico pensar que los fragmentos de las armaduras custodiados en el Museo Arqueológico Provincial pasaron a formar parte de esta colección entre 1944, última noticia de la Comisión de Monumentos, y 1948.

De la armadura del salón conocemos que su estado era, cuanto menos, precario hacia 1870, según indica de la Rada y Delgado. No es extraño que pudiera formar parte del grupo de cubiertas cedido por el Gobernador Militar a la Comisión de Monumentos hacia $1885^{20}$. A pesar de que constan algunas adquisiciones como las de un ajimez y dos preciosos arcos mudéjares que el Gobierno Militar entrega al museo de León después de ser descubiertos en el cuartel de la fábrica, a finales del siglo XIX, no se manifiestan noticias de las cubiertas del Palacio Real en las guías y catálogos de la primera mitad del siglo $X X^{21}$. De todo ello se desprende que esta techumbre nunca engrosó la colección del Museo de León. Cuál fue su destino o si, realmente, sucumbió dentro del Palacio es una incógnita. Lo mismo sucede con la armadura de la caja de

\footnotetext{
${ }^{19}$ M. DOMínguez BerRuetA, Guías artísticas de España, León, Barcelona, 1953, p. 150.

${ }^{20}$ El 1 de marzo de 1894 se recogen, por la Comisión de Monumentos de León, una serie de bienes artísticos y arqueológicos que pasan a formar parte de las colecciones del museo leonés. En este inventario no aparece ninguna pieza procedente del antiguo Palacio Real. B.P.L. Comisión de Monumentos, "Inventario que por acuerdo de la comisión de monumentos...", Ms. 55, 1894.

${ }^{21}$ Cfr. , E. DíAZ-Jimenez y MolledA, Historia del museo arqueológico de San Marcos de León. Apuntes para un catálogo, Madrid, 1920; Á. NIETO, Guía histórico descriptiva del Museo Arqueológico Provincial de León, Madrid, 1925.
} 
la escalera situada en el ángulo Sur-Oeste del Palacio Real.

En consecuencia, los únicos fragmentos de aquella espléndida carpintería de lo blanco, que han perseverado hasta nosotros, se encuentran conservados en el $\mathrm{Mu}$ seo de León, al que llegaron entre 1944 y 1948 (lám. III). Es sobre estos fragmentos, además de los testimonios fotográficos señalados, en los que podemos centrar nuestro estudio, tratando de aportar datos sobre sus características, tipología y cronología.

\section{EL LAZO DE LAS ARMADURAS DEL PALACIO REAL DE LEÓN.}

a) La incorporación de la lacería en la carpintería de lo blanco.

Los vestigios arqueológicos $\mathrm{y}$ fotográficos permiten atestiguar la existencia de, al menos, cuatro armaduras de madera dentro del Palacio Real de León, cubriendo dependencias diferentes. A pesar de su distinta ubicación, este grupo está fuertemente vinculado entre sí desde el punto de vista artístico. La ornamentación geométrica de las mismas aparece concentrada en el almizate y ésta se repite idénticamente en los cuatro ejemplos, por lo que parece probable que todas ellas se realizaran dentro de un mismo marco cronológico y por los mismos maestros carpinteros ${ }^{22}$.

\footnotetext{
${ }^{22}$ Las bases del siguiente estudio parten, de los fragmentos depositados en el Museo de León, así como de los testimonios gráficos obtenidos del Archivo Municipal de León y del Archivo de la Comandancia de Obras de Valladolid. De la cubierta de la caja de la escalera tenemos la certeza que era gemela a la que cubría la gran sala y que aún observó Rada. La documentación fotográfica permitió corroborar que los restos de las techumbres conservados en el Museo de León, que pertenecen a dos cubiertas diferentes, eran idénticos a la armadura de la escalera. De ahí que los cuatro trabajos en madera de los que teníamos cons-
}

Los tratados de carpintería de lo blanco que han llegado hasta nosotros manifiestan las facilidades para construir armaduras idénticas gracias a un proceso que podíamos calificar de "seriado"23. Este trabajo era factible gracias a las posibilidades que ofrecía la realización del mismo ex proceso, prefabricando la armadura. Los distintos integrantes de la techumbre de madera se realizaban por varios carpinteros que obraban simultáneamente para ajustar, posteriormente, las piezas in situ con toda perfección. La labor de personal especializado en la construcción de las obras de carpintería de lo blanco queda patente en muchas de estas empresas, lo que permite comprender la repetición de estos trabajos con características casi idénticas.

En cuanto al entramado geométrico de los restos llevados a estudio, el carpintero parte de una retícula base formada por los maderos estructurales, puesto que la técnica adoptada es la del lazo apeinazado. De este modo, los elementos constituyentes forman parte de la trama decorativa, por lo que el artífice esta sujeto a las limitaciones de esa retícula base estructural. Se trata de una decoración geométrica sencilla, tanto que se ha dicho de ella que podía ser la

-

tancia respondían a un mismo modelo decorativo y estructural.

${ }^{23}$ Los tratados conservados de carpintería de lo blanco más importantes pertenecen al siglo XVII. Vid. D. LOPEZ DE ARENAS, Breve compendio de la carpintería de lo blanco y tratado de alarifes, $1^{\underline{a}}$ ed. Sevilla, 1633. Otra obra destacada es la de Fray Andrés de San Miguel, conocida gracias a la obra publicada por Baez Macías. E. BAEz MACíAs, Obras de Fray Andrés de San Miguel, Méjico, 1969. Posteriormente ambos tratados han sido objeto de numerosas publicaciones, ediciones anotadas y estudios dibujados. Vid.: E. NuERE MATAuCO, La carpintería de lo blanco. Lectura dibujada del primer manuscrito de Diego López de Arenas, Madrid, 1985; E. Nuere Matauco, Nuevo tratado de la carpintería de lo blanco, Madrid, 2001; D. LOPEZ DE ARENAS, Breve compendio de la carpintería de lo blanco, Madrid, 1997, edición anotada de María Ángeles Toajas Roger; E. NUERE MATAUCO, La carpintería de lazo. Lectura dibujada del manuscrito de Fray Andrés de San Miguel, Málaga, 1990. 
base de las complejas ruedas de lazo desarrolladas con posterioridad.

El devenir de la carpintería de lo blanco pudo comenzar con la búsqueda y el deseo, por parte de los carpinteros, de crear un sistema que posibilitara la prefabricación de la armadura, objetivo más útil, no solo para conseguir elaborar el trabajo en el taller, sino también, para obtener un desarrollo "en cadena" de la producción de estas cubiertas mediante el uso de cartabones. Este hecho fue el que llevó a los carpinteros a desarrollar el sistema de limas dobles o moamares, de manera que cada una de ellas quedaba integrada en un paño y conseguía dar cohesión y estabilidad a cada uno de ellos ${ }^{24}$. Por su parte, el almizate o harneruelo debía integrar algún elemento de unión similar para poder prefabricarse y también para poder soportar el posterior empuje de las limas y de los pares. De ahí que, según algunos estudiosos, pudieron apeinazarse los nudillos en los extremos logrando cierta rigidez. El entramado cuadriculado exterior pudo repetirse por el resto del almizate; así, de esa retícula a un simple conjunto de estrellas hay un pequeño camino. Mediante este procedimiento, pudo surgir, casi inevitablemente, la estrella de ocho en el almizate ${ }^{25}$.

\footnotetext{
${ }^{24}$ La documentación gráfica de los ejemplos que llevamos a estudio ha permitido observar que esta misma tipología constructiva de limas moamares o dobles fue la utilizada para elaborar la armadura de la caja de la escalera.

${ }^{25}$ Esta teoría de la generación del lazo en las cubiertas de madera es defendida por Enrique Nuere, Vid. E. NUERE MATAUCO, La carpintería de armar española, Madrid, 1989. p. 88; E. NUERE MATAUCO, La carpintería de lo blanco... , p. 23. En esta misma línea de estudio sobre la gestación de los trazados de lacería, en la carpintería de lo blanco, partiendo de este lazo simple se encuentran las publicaciones de algunos expertos como Prieto Vives; A. PRIETO VIVES, El arte de la lacería, Madrid, 1977, p. 53. Asimismo, defiende la posible paternidad hispana del mismo; A. PRIETO VIVES, Op. cit., p. 80. Esta misma afirmación es sostenida por otros investigadores; M. FERNÁNDEZ CABO, Cubiertas de
}

El investigador Enrique Nuere demuestra de manera gráfica, en uno de sus estudios, la facilidad de la generación de este trazado simple de estrella de ocho puntas por medio de limas moamares junto a las manguetas de los paños. La estrella de ocho se genera con una pretensión funcional: dar rigidez al almizate ${ }^{26}$. El diseño geométrico desarrollado forma un lazo reticular. Sobre el retículo base se establece la sucesión de estrellas con alguna variación pero que deja entrever la trama reticular empleada.

Esta concentración del trazado de estrellas de ocho puntas comenzaría en el almizate, pero por razones técnicas y estéticas pasaría rápidamente a formar parte del resto del conjunto lígneo. Por su parte, la inclusión de la estrella de cuatro o cruceta no sería más que la consecuencia de prolongar los elementos que componen las estrellas de ocho cuando se disponen en forma de damero ${ }^{27}$.

Para muchos expertos, los complejos trazados geométricos de ruedas de lazo, generados posteriormente, fueron incorpo-

madera, Valladolid, 1997, pp. 185 y 190; M. FERNÁNDEZ $\mathrm{CABO}$, "De los orígenes y desarrollo de las armaduras de cubierta latinas", Actas del I Congreso Nacional de Historia de la Construcción, Madrid, 1996, pp. 305-312. Por otro lado son muchas las alusiones de autores al origen euclidiano de toda la geometría de la carpintería de lo blanco. Vid.: M. FERNÁNDEZ CABO, Cubiertas de... p. 177; G. Duclos BAuTISTA, Carpintería de lo blanco en la arquitectura religiosa de Sevilla, Sevilla, 1992. p. 39. Otros autores como Basilio Pavón Maldonado han dejado entrever la filiación que, con la geometría del mundo clásico, tuvieron los trazados geométricos islámicos y mudéjares. B. PAVÓN MALDONADO, “ La decoración geométrica hispanomusulmana y los cimborrios aragoneses de tradición islámica", I Simposio Internacional de Mudejarismo, Teruel, 1981, pp. 177-209; B. PAVÓN MALDONADO, El arte hispanomusulmán en su decoración geométrica. Una teoría para un estílo, Madrid, 1975. 90.

${ }^{26}$ E. NuERE MATAUCO, La carpintería de armar..., p. ${ }^{27}$ Ibidem, p. 91. 
rados del arte hispanomusulmán pero pudieron adecuarse a la carpintería de lo blanco gracias al sistema español de cartabones ${ }^{28}$.

A pesar de que las hipótesis expuestas hacen gala de una gran consistencia, no conocemos, fidedignamente, cómo se incorporaron los motivos de lazo en las estructuras de las cubiertas de madera. Sin embargo tenemos constancia de que éstos existen desde el siglo XIV, que se originan como una simple sucesión de estrellas de ocho y que llegaron a un apogeo en el siglo XV con la dinastía Trastámara, lo cual corrobora las anteriores conjeturas.

Así mismo, en todas estas armaduras dotadas de lacería existe una adecuación del espacio al trazado geométrico seleccionado, hecho lógico si tenemos en cuenta que la propia trama geométrica impone su ley formal y configura el poliedro que forma la armadura ${ }^{29}$. Por otra parte, existe una estricta relación entre cartabones de armadura y de lazo, puesto que la inclinación de los faldones es básica para que el corte entre planos se realice en determinados ejes de la trama geométrica. Esta es la razón por la que en primer lugar se escoge la trama geométrica y posteriormente la inclinación adecuada para ésta ${ }^{30}$.

En todo caso, lo que realmente marca las diferencias entre las armaduras españolas del resto de sus contemporáneas europeas es la aplicación a las mismas de un trazado geométrico: el lazo.

\footnotetext{
${ }^{28}$ A. PRIETO VIVES, Op. cit., p. 60. 147.

${ }^{29}$ E. NUERE MATAUCO, La carpintería de armar... p.

${ }^{30}$ E. NUERE MATAUCO, “Los cartabones como instrumento exclusivo para el trazado de lacerías. La realización de sistemas decorativos geométricos", Madrider Mitteilungen, Mainz, 1982, pp. 374-375.
}

b) Lazo de estrellas de ocho y cuatro. El lazo reticular.

Los ejemplos de armaduras del desaparecido Palacio Real leonés integran en sus almizates una decoración geométrica basada en el encadenamiento de estrellas de ocho puntas y lacillos de cuatro que, como hemos puesto de manifiesto, pudo ser fruto de la búsqueda de prefabricación de las mismas y el origen de la incorporación de lacería en la carpintería de lo blanco. Ahora llevaremos a cabo el estudio de este tipo de ornamentación geométrica.

Uno de los más importantes estudiosos de la lacería, Antonio Prieto Vives, identifica esta labor como lazo de cuatro, puesto que detenta simetría cuadrangular, es decir, simetría de cuarto orden ${ }^{31}$. Dicho lazo, calificado por Vives de lazo sencillo $\mathrm{u}$ ordinario, está ordenado por temas que ocupan posiciones paralelas entre sí, siendo las líneas paralelas a cuatro posiciones distintas. La única alteración de todo el entramado decorativo se sitúa en el centro del almizate como consecuencia del emplazamiento de un racimo de mocárabes de base octogonal. Este ejercicio explica la supresión y variantes de algunos enlaces del trazado de estrellas de 4 y 8 puntas alrededor de dicho octógono. A través de esta práctica se consigue proporcionar continuidad visual al entrelazado a la vez que se elimina la monotonía del diseño geométrico de estrellas y crucetas.

Como consecuencia de estos procedimientos, la decoración del almizate, de los ejemplos del Palacio Real, incorpora estrellas de ocho de puntas de $90^{\circ}$ y de $45^{\circ}$ además de crucetas o estrellas de cuatro ${ }^{32}$.

\footnotetext{
31 A. PRIETO VIVES, Op. cit., p. 32.

${ }^{32}$ Resulta bastante significativo tanto que estos modelos de lazo fueron principalmente realizados por la dinastía Trastámara, como que para llevar a cabo este tipo de ornamentación geométrica era necesario el empleo de cartabones similares a los utilizados para la
} 
En todo caso, la traza geométrica generada por esta sucesión de estrellas forma un lazo reticular, es decir, un lazo o diseño geométrico que parte de una retícula base (fig. 1).

Este lazo reticular formado por estrellas de ocho y cuatro puntas, denominado por algunos historiadores "lazo occidental" o "andalúz"33, basado en estrellas de ocho de primer o segundo cruce -esto es, estrellas de $90^{\circ}$ o de $45^{\circ}-$, está ordenado mediante un canon proporcional de medida tal como afirmara Fernández Puertas, de forma que estos diseños de ocho podían generarse completamente sobre una cuadrícula ${ }^{34}$. Siguiendo estas teorías obtenemos que la labor geométrica de las armaduras palatinas leonesas, llevadas a estudio, se habría formado sobre una cuadrícula o malla de siete partes de lado, por medio de estrellas de ocho de primer cruce, que han formado en su intersección espacios en forma de aspa o cruz, llamados lacillos de cuatro, crucetas o estrellas de cuatro. Las variantes son múltiples si tenemos en cuenta la facilidad, como sucede en los ejemplos de techumbres del Palacio Real, para establecer supresiones mediante la eliminación de partes del trazado, o variantes en el mismo.

Por otra parte, parece que este tema geométrico del lazo formado por estrellas

construcción de armaduras, por ejemplo el cartabón cuadrado de $45^{\circ}$ era necesario para la configuración de esta estrella de ocho y a su vez podía dar la pendiente o inclinación de los faldones de la armadura. Si bien, lo habitual era configurar la pendiente con el cartabón de 5 que confería una inclinación de $36^{\circ}$ a los faldones. Cfr. E. NUERE MATAUCO, La carpintería de armar,... p. 194. Vid. E. NUERE MATAUCO, Los cartabones como... pp. 372-427.

${ }^{33}$ Cfr. A. Fernández Puertas, "El lazo de ocho occidental o andaluz. Su trazado, canon proporcional, series y patrones", Al-Andalus, vol. XL, 1975, pp. 199203.

${ }^{34}$ Ibidem, Idem; A. DONAIRE RODRíGUEZ, "El trazado de lacería de ocho en alicatados", Actas del III Simposio de Mudejarismo, Teruel, 1986, pp. 647-674. Estas ideas refrendan el carácter reticular de este lazo. de ocho y cuatro pudo ser el origen del lazo reticular de ocho con zafates harpados, derivado de la incorporación de ocho estrellas de ocho puntas alrededor de otra de ellas, suprimiendo la parte del trazado que es incompatible. Esta operación da como resultado el lazo reticular tan característico de la provincia leonesa, que tiene su máximo exponente en el forjado de piso de la sala capitular del antiguo convento de San Marcos en León, realizado en el siglo XVI ${ }^{35}$.

La técnica utilizada para la configuración, tanto de la estructura como de la ornamentación y diseño geométrico de estas cubiertas, es la apeinazada, siguiendo el procedimiento de separación de calle y cuerda $^{36}$. Si bien hemos podido comprobar que el modelo leonés no se ajusta exactamente a esta proporción, es habitual que ésta se soslaye sistemáticamente en las armaduras apeinazadas ${ }^{37}$. Por otra parte,

-

${ }^{35}$ Sobre este lazo reticular vid: J. GARCíA NISTAL, "El lazo reticular: una solución constructivo-decorativa en la carpintería de lo blanco de la provincia de León", Boletín del Instituto "Camón Aznar", no 90, Zaragoza, 2003, pp. 55-76.

${ }^{36}$ En el lazo apeinazado son los propios elementos estructurales y autoportantes de la armadura los que configuran la labor decorativa de la misma. Asimismo, estos trabajos apeinazados son utilizados mayoritariamente durante los siglos XIV y XV, relegados posteriormente por los trabajos de lazo ataujerado.

${ }^{37}$ J. Galiay SARAÑANA, El lazo en el estilo mudéjar, su trazado simplicista, ed. facsímil, Zaragoza, 1995, p. 18. Igualmente, Enrique Nuere cree que, a pesar de establecerse la separación de vigas en el doble de su grueso (proporción de calle y cuerda), es cierto que no era extraña una mayor separación. Cfr. E. NUERE MATAUCO, La carpintería de armar... pp. 54-56. Hemos podido comprobar, mediante el estudio de los restos conservados en el Museo Arqueológico de León, que la separación entre las cuerdas no se corresponde exactamente con el doble de su grueso. La medida de las cuerdas es de $9^{\prime} 5 \mathrm{~cm}$. y el de la calle de $24^{\prime} 5 \mathrm{~cm}$. Esta irregularidad se debe, seguramente, a la búsqueda de una proporción más conveniente para la adaptación del trazado reticular a la estructura de los maderos. Quiero mostrar mi gratitud a D. Luis Grau Lobo, director del Museo de León, quien me permitió el 
parece que ya desde al menos el siglo $\mathrm{XV}, \mathrm{y}$ quizás antes, las armaduras se realizaban con anchos de maderas que se pueden denominar "comerciales", por lo que su trazado casi siempre era obligado que se hiciera fuera de calle y cuerda ${ }^{38}$.

Debemos precisar que en esta labor de lazo apeinazado, parte de la misma se realiza con tablillas superpuestas y se añaden, en los encuentros entre nudillos y peinazos, unos tacos triangulares cuyas caras se enrasan con los rebajes de nudillos y peinazos para completar estrellas de ocho en el plano rebajado. Del mismo modo, puesto que algunos elementos estructurales no se integran en el trazado debido, en gran parte, a la incorporación del racimo de mocárabes, se añaden tablillas superpuestas, con bordes biselados y aspecto formal de estrellas de ocho puntas de segundo orden, que ocultan la verdadera estructura de la cubierta.

Técnicamente, queda por añadir la pauta utilizada para el ensamble de las piezas que configuran, estructural y decorativamente, todo el conjunto. Los peinazos se ensamblan con los nudillos del almizate mediante la solución a caja y espiga, si bien el enlace del dibujo geométrico utiliza el encastado a romo, modelo muy difundido dentro de los trabajos de la carpintería de lo blanco de la provincia de León.

Cabe destacar, dentro del diseño geométrico de estos almizates, un elemento que cumple una labor decorativa y funcional al mismo tiempo. Se trata del agramilado o líneas incisas en el papo de los nudillos y peinazos que discurren paralelamente a la dirección de los anteriores. Con este recurso ornamental se consigue reforzar el

estudio de estos dos fragmentos básicos para el artículo realizado.

${ }^{38}$ E. Nuere Matauco, La carpintería de lazo..., p. 100. efecto de entrelazado y conferir continuidad al mismo. Otra de las soluciones técnica y ornamental, aplicada a los almizates, pasa por tapar el espacio u oquedad generada en las estrellas de ocho puntas. En el trasdós de la cubierta se aplica una sencilla tablazón para salvar estos espacios. Ésta incorpora, en su parte visible, una fosilla excavada en la madera formada por ocho gallones o gajos.

Una última labor que completaría la suntuosidad de estos ejemplos es la aplicación de policromía a algunos de los integrantes de la cubierta. De ese modo, se aplican valores cromáticos a los gramiles o líneas incisas, besantes blancos sobre fondo negro en los perfiles biselados de las estrellas de ocho de segundo cruce y las generadas mediante variantes y supresiones $\mathrm{y}$ dorados en los gallones y racimos de mocárabes.

c) Otras soluciones decorativas. La labor de menado y los mocárabes.

Hemos realizado un estudio constitutivo y formal del almizate de las techumbres del Palacio Real de León partiendo de fotografías, así como de los escasos fragmentos que han perdurado hasta hoy. Seguidamente, analizaremos el resto de los elementos de las cubiertas, labor que ha sido posible a través del material gráfico ${ }^{39}$.

\footnotetext{
${ }^{39}$ Sólo pudimos estudiar, en su totalidad, la estructura de la cubierta de la caja de la escalera, mediante las fotografías del Archivo Histórico Municipal de León y los fragmentos del Museo Provincial junto a la documentación gráfica de los mismos obtenida en el Archivo de la Comandancia de Obras de Valladolid. Estas fuentes permitieron, del mismo modo, obtener las proporciones de las estancias que cubrían. Haciendo uso de las proporciones seguidas por los carpinteros de lo blanco: el almizate se situa a $2 / 3$ de la altura de los pares y ocupa $1 / 3$ del ancho a cubrir, el número de peinazos de cada almizate es 6; puesto que, existe una proporción cercana a la calle y cuerda, el número de gruesos que integran el almizate es de $18 \mathrm{y}$ el del
} 
La tipología estructural o constructiva a la que pertenecen las techumbres estudiadas se corresponde con el grupo de las armaduras de pares. Concretamente, la ubicada en la caja de la escalera es una cubierta de limas moamares, de tres paños y formalmente es una techumbre de sección cuadrada, dotada de cuadrales y aguilones en los ángulos de la misma. Los fragmentos custodiados en el Museo de León, que a buen seguro cubrían dos de los salones del palacio, pertenecen a cubiertas de par y nudillo, de tres paños y de sección rectangular (fig. 2$)^{40}$.

En cuanto al tipo de material empleado, probablemente fuera el mismo para todos estos ejemplos de carpintería del Palacio Real de León. Únicamente conocemos el de los fragmentos del Museo de León: madera de pino ${ }^{41}$.

Comprobamos, anteriormente, que la agrupación del trabajo más opulento y espinoso de todo el conjunto se concentraba

ancho de toda la cubierta es 54 . El grueso del par o cuerda mide 9,5 y la calle $24^{\prime} 5$ por lo que el ancho total de la estancia que cubrían estas cubiertas depositadas en el museo era de $6^{\prime} 12 \mathrm{mts}$., la misma proporción del ancho que cubría la caja de la escalera que ocupa un espacio de 6'12 × 6'12 mts. Este dato, permite suponer que los fragmentos localizados en el Museo Arqueológico de León pertenecían a techumbres ubicadas en los corredores anejos al patio que, al igual que la cubierta de la caja de la escalera, estarían situadas en la parte occidental del antiguo palacio.

${ }^{40}$ Los fragmentos del Museo de León pertenecían a dos cubiertas diferentes de par y nudillo. En los lados mayores de estos, se observa una interrupción en la sucesión del lazo. Este hecho indica que estas armaduras no tenían continuidad con faldones en estos lados mayores, de modo que serían cubiertas a dos aguas. Esto mismo nos llevó a presumir que una de las cubiertas depositadas en el museo, fragmentada en uno de sus lados mayores, pudo tener mayores dimensiones, tal como indica el lugar donde se resquebrajó.

${ }^{41}$ J. LAVAdo PARAdinas, Pedro, “Arte mudéjar en el convento de las concepcionistas de León y su entorno: la calle de la Rúa", la orden concepcionista. Actas del Ier Congreso Internaconal, León, 1990 p. 364. en el almizate, reduciéndose a fórmulas más sencillas en las gualderas o faldones del conjunto lígneo.

La cubierta mejor documentada gráficamente era la perteneciente a la caja de la escalera. En las fotografías, pudimos observar que, para cubrir el espacio resultante entre los pares de los faldones, se recurre a la labor de cinta y saetino. Transversalmente a la línea de pares, por el trasdós de la techumbre, se clavetean tablas o cintas que, a la vez que ayudan a conferir una cierta cohesión a los anteriores, ofrecen un rico efecto ornamental mediante sus perfiles recortados y el biselado de sus bordes que labran un diseño geométrico. Entre estas cintas y los pares se genera un espacio que se cubre por medio de tablas de sección trapezoidal biseladas, dispuestas paralelamente a la dirección de los pares, que se conocen con el nombre de saetín o saetino.

Toda esta labor que hemos descrito también es conocida como labor de menado y puede tomar su nombre precisamente por el vocablo almenado, es decir, con ventanas, haciendo alusión al aspecto de las oquedades que quedan entre las cintas y los pares.

Estas oquedades o espacios se solventan mediante una simple tablazón o guardapolvos que llevaba incorporada decoración policromada de hojas vegetales esquemáticas e incluso la talla de algunas chillas o fosillas gallonadas formadas por ocho gajos. El agramilado, que formaba parte de la ornamentación del almizate, es otro de los recursos decorativos incorporados en los papos de los pares que configuran las gualderas ${ }^{42}$.

\footnotetext{
${ }^{42}$ No pudimos documentar si este mismo modelo de trabajo empleado para los faldones de la armadura de la caja de la escalera, fue el utilizado en el resto de armaduras estudiadas. Si bien, las similitudes en el resto de labores, permite suponer que la técnica adoptada fue afín.
} 
Como punto final a este estudio constructivo-decorativo de las cubiertas del Palacio Real leonés analizamos los mocárabes como principios claves dentro de la traza geométrica y ornamental de las mismas.

Los mocárabes son estructuras no resistentes, meramente decorativas. Sin embargo, ocupan un lugar privilegiado dentro de estos conjuntos lígneos: el centro del almizate y de todo el entramado del lazo reticular. El tema compositivo de los mismos tiene una clara influencia islámica. Sobre la paternidad de tales motivos decorativos no existen grandes controversias entre los investigadores, si bien es cierto que, para algunos de ellos, la aparición de los mismos en la carpintería de lo blanco pudo ser fruto de la adaptación de este modelo ornamental a los métodos y prácticas de trabajo de los carpinteros hispanos ${ }^{43}$.

En nuestro estudio sobre la lacería de los almizates leoneses observamos que ésta se interrumpía por medio de un octógono destinado a recoger un racimo de mocárabes. Hecho que pudimos corroborar y analizar gracias a las fotografías de la cubierta de la caja de la escalera y de los fragmentos depositados en el Museo de León.

Los racimos de mocárabes son un elemento que combina cierta libertad compositiva y cierta restricción a la vez ${ }^{44}$. Los desaparecidos racimos de mocárabes de las cubiertas del Palacio Real leonés siguen un mismo modelo; están formados por adarajas o piezas de madera agrupadas alrededor del nabo central o pieza ochavada. Toda la estructura queda sujeta mediante una telera o pasador que se incorpora en el trasdós de la cubierta, fuera del alcance visual del

\footnotetext{
${ }^{43}$ Baste citar algunos ejemplos; E. NUERE MATAUCO, La carpintería de armar... p. 159; A. PRIETO VIVES, Op. cit., p. 223.

${ }^{44}$ A. PRIETO VIVES, Op. cit., p. 224.
}

espectador. Cada adaraja se forma gracias a unas plantillas formando cada perfil de estos prismas que tienen lados de valores 5 y 7. Jugando con las diferentes secciones se pueden combinar de muy diferentes maneras $^{45}$.

En los ejemplos concretos del Palacio Real se utilizan los cuatro tipos esenciales de adarajas: el dumbaque o triángulo isósceles con lados mayores de valor 5, el medio cuadrado o triángulo rectángulo isósceles (de lados valor 7 y 5), la conça o prisma rectangular con lados de proporciones $7 \mathrm{y}$ 5; y por último la jaira o prima romboidal con lados de valor 5 . La combinación de todos estos prismas con algunas variantes dentro de sus formas básicas da como resultado la formación del racimo de mocárabes. Para el mejor entendimiento de la formación de esta pieza véase dibujo (fig. 3 y lám. IV).

\section{CRONOLOGÍA Y CONCLUSIONES.}

La sencillez de este lazo reticular y de su diseño geométrico, formado por estrellas de ocho y lacillos de cuatro, pudo ser, como hemos analizado, generadora de la incorporación de entramados de lacería más complejos dentro de la carpintería de lo blanco peninsular. Conocer el foco creador del mismo parece una tarea harto difícil debido a la escasez de fuentes documentales con las que contamos.

Este trazado geométrico se difundió por diversos puntos geográficos de nuestra península y lo encontramos, generalmente, asociado a la monarquía castellana de los siglos XIV y XV y, concretamente, ligado a dos figuras claves de la arquitectura civil

\footnotetext{
${ }^{45}$ Para conocer la generación de todos estos mocárabes vid: A. PRIETO VIVES, Op. cit., pp. 223-248; E. NUERE MATAUCO, La carpintería de armar... pp. 159-169; E. NUERE MATAUCO, La carpintería de lazo... pp. 263-284.
} 
española de la segunda mitad del siglo XIV: Pedro I y Enrique II.

Uno de los primeros ejemplos de la aparición de este lazo en la carpintería de armar española lo encontramos en la cubierta de la Sinagoga del Tránsito en Toledo, obra encargada por Samuel Haleví, tesorero de Pedro I de Castilla a mediados del siglo XIV. En ella, la trama generada por estrellas de ocho puntas y lacillos de cuatro queda patente en el almizate.

De la segunda mitad del siglo XIV, tenemos noticia de los reales alcázares de Tordesillas y de Astudillo. Del primero de ellos, obra de Alfonso XI hacia 1340, si bien la parte más destacada se debe a las reformas y ampliaciones de su hijo Pedro I entre 1354-1361, a penas nos quedan restos de las ricas techumbres que engalanaron las dependencias de este palacio. Sobre las mismas conocemos algunas referencias, como la que ornamentaba y cubría el salón central de grandes dimensiones -que recuerda las noticias sobre la cubierta de la gran sala del Palacio Real leonés- y otras como la del salón meridional ${ }^{46}$. En este alcázar, observamos la incorporación del lazo formado por estrellas de ocho y crucetas en otro tipo de cubiertas como la base de la cúpula semiesférica de yeso que cubre la capilla dorada.

Por su parte, el convento-palacio de Santa Clara de Astudillo, en la provincia de Palencia, es fundado en 1354 por María Padilla, esposa de Pedro $\mathrm{I}^{47}$. El tipo de $\mathrm{cu}^{-}$

\footnotetext{
${ }^{46}$ C. GARCÍA-FrÍAs CHECA, "El palacio mudéjar de Tordesillas", Los alcázares reales, Madrid, 2001, pp. 7397.

${ }^{47}$ P. J. LAVADO PARADINAS, "Carpintería y otros elementos típicamente mudéjares en la provincia de Palencia, partidos judiciales de Astudillo, Baltanás y Palencia", Tello Téllez de Meneses, no 38, Palencia, 1977, pp. 7-234; P. J. LAVADO PARADINAS, "El palacio mudéjar de Astudillo", Actas del II Congreso de Historia de Palencia, Palencia, 1990, pp. 579-599.
}

bierta utilizado para techar el cuerpo de la nave central utiliza el mismo trazado de estrellas de ocho puntas y crucetas que hemos estudiado, si bien se trata de un modelo más sencillo dotado de algunas supresiones.

Este mismo lazo reticular forma parte de la armadura de madera del convento de las Dueñas, hoy depositada en el Museo de Salamanca, que data de finales del siglo XIV.

Nuevamente en Toledo, se ubican las "casas de San Antolín", antiguo palacio que, en manos de Fernando el Católico, pasaron a convertirse en convento de Santa Isabel de los Reyes. Estas casas pertenecieron a la familia de los Gómez de Toledo, entre los herederos, volvemos a encontrarnos con un personaje vinculado a las figuras de los reyes Pedro I y Enrique II, Diego Gómez de Toledo, alcalde mayor de la ciudad de Toledo y notario "por el rey D. Pedro"48.

El tipo de entramado geométrico, muy similar al de las cubiertas del alcázar leonés, corresponde a la cubierta de la Sala de la Fundadora de este convento toledano. Gracias a los vestigios heráldicos se conoce que fue elaborada en tiempos de Juana Enríquez antes de su matrimonio con Juan II, por lo que la cronología de la misma se establece entre $1453-1458^{49}$. Si bien esta cubierta pudo ser construída siguiendo algunos modelos anteriores de la época de Pedro I.

\footnotetext{
${ }^{48}$ B. Martínez Caviro, Conventos de Toledo, Madrid, 1990, p. 109; B. MARTíNEZ CAVIRO, "Sobre las armaduras de madera en el arte mudéjar toledano", Actas del Congreso Internacional de Historia del Arte. España entre el Mediterráneo y el Atlántico, Granada, 1973, pp. 139-150; B. MARTÍNEZ CAVIRO, "El arte en los conventos de Toledo", I ${ }^{e r}$ Congreso Internacional del monacato femenino en España, Portugal y América, tomo II, León, p. 496.

49 B. Martínez Caviro, Conventos de Toledo, p. $142-150$
} 
Ante esta relación, se hace patente que el trazado de estrellas de ocho y lacillos de cuatro se manifiesta en una serie de edificios, la mayoría de ellos de la arquitectura civil española, generalmente en alcázares reales, auspiciados bajo el patrocinio regio de los monarcas castellanos del siglo XIV Alfonso XI, Pedro I y Enrique II particularmente-, o en edificios de familias nobles vinculadas con los anteriores de alguno $\mathrm{u}$ otro modo.

Todo ello, junto a la notoria dependencia y admiración artística de Castilla con el mundo andalusí en lo referente a la arquitectura civil palatina hacia mediados del siglo XIV y el mudejarismo manifiesto en la vida de la sociedad hispana de la Baja Edad Media, dan como fruto unas intensas relaciones sociales, culturales y artísticas entre las sociedades hispana y andalusí.

Este panorama de convivencia cultural, pudo ser la fuente de incorporación de la lacería a las estructuras tradicionales de cubiertas de la carpintería de lo blanco hispana, a través de los modelos ornamentales del arte hispano-musulmán que inspiraron la creación artística de los carpinteros españoles.

Existe, por otra parte, una continua conexión de unos núcleos bien diferenciados, Toledo, Astudillo, Tordesillas y León. Ésta puede ser la línea de corriente que llevó los trazados geométricos de unos lugares a otros. De modo que las artes hispano-musulmanas, con sus motivos ornamen- tales basados en los juegos geométricos, pudieron dar paso a la inspiración de los carpinteros de lo blanco hispanos, que no tuvieron mucha dificultad en aplicar algunos sencillos diseños a las retículas de sus cubiertas de madera. El punto intermedio pudo ser Toledo, con algunos ejemplos inspiradores y precursores, como la cubierta de la Sinagoga del Tránsito, pasando desde ahí a Castilla y León (Salamanca, Astudillo, Tordesillas), para llegar definitivamente a la propia ciudad de León en manos de la monarquía de Enrique II.

La homogeneidad constructiva y formal, de todos estos ejemplos de armaduras de madera, también viene dada en el marco cronológico en el que se engloban, entre mediados del siglo XIV y mediados del siglo XV. Dentro de este mismo espacio temporal, se sitúan las cubiertas del Palacio Real de León, del año 1377. Prueba de ello es su técnica apeinazada, el uso de agramillado en el papo de sus integrantes, los racimos de mocárabes y las fosillas gallonadas, elementos constructivos y ornamentales de mediados del siglo XIV.

Concluyendo, la segunda mitad del siglo XIV, momento en el que se elaboran las cubiertas del desaparecido Palacio Real de León, y el siglo siguiente supusieron el periodo de mayor auge y esplendor de la denominada carpintería mudéjar. En este florecimiento de la carpintería de lo blanco jugó un importantísimo papel el patrocinio artístico de los monarcas castellanos bajomedievales. 


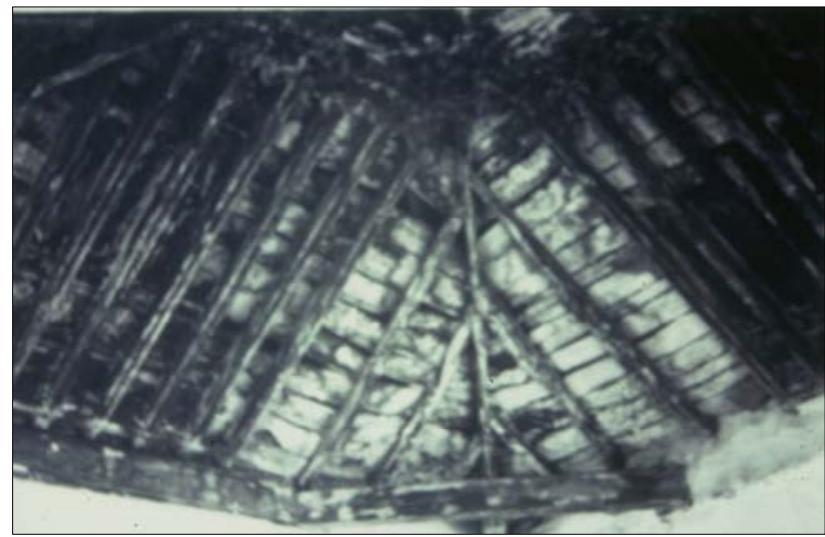

- Lám. I. Cubierta de la caja de escalera en el antiguo Palacio Real leonés. Archivo Histórico Municipal de León (arriba izquierda, arriba derecha)
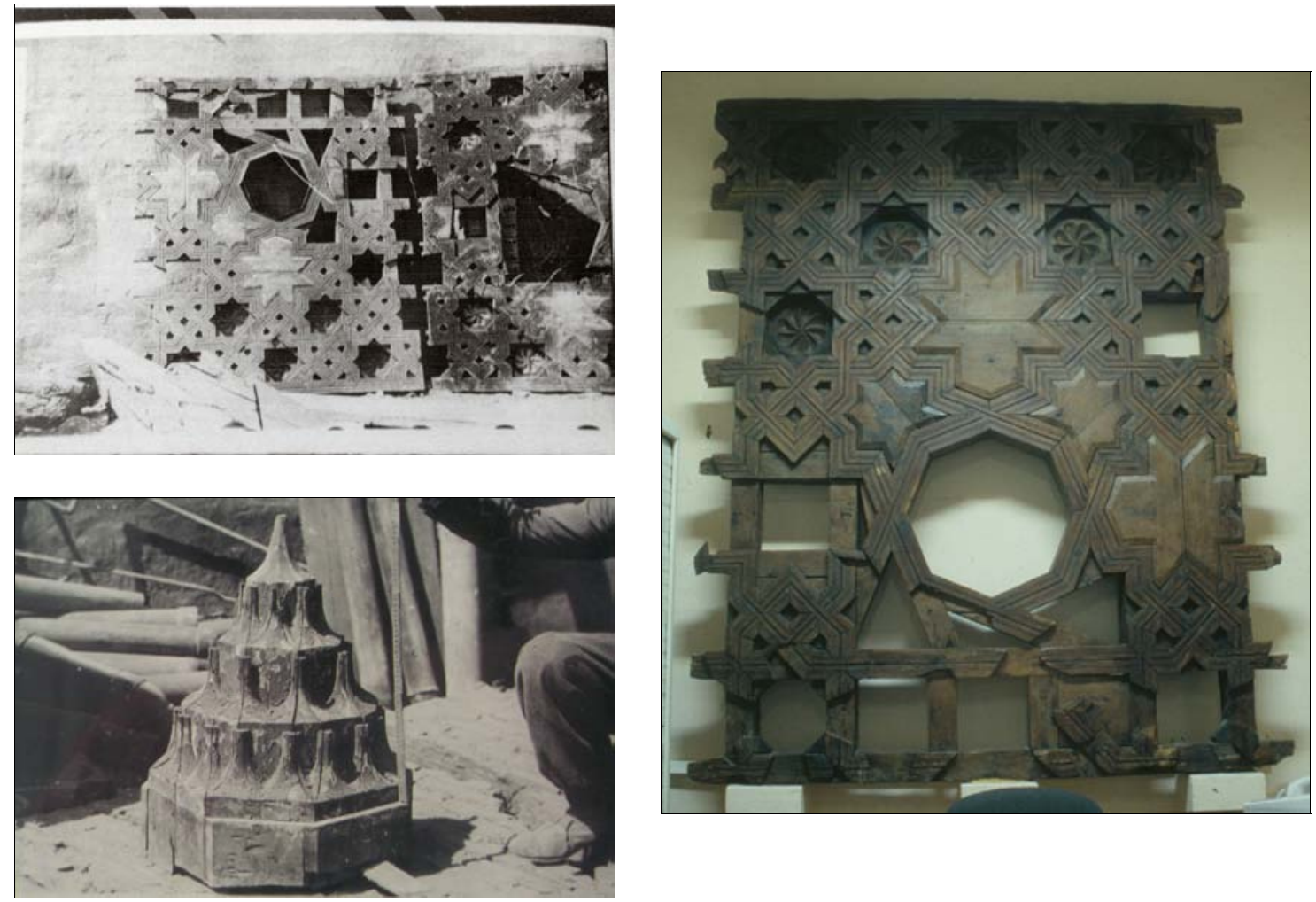

- Lám. II. Fragmentos de dos armaduras del Palacio Real depositadas actualmente en el Museo de León. Fotografía: Archivo de la Comandancia de Obras de Valladolid (centro izquierda)

- Lám. III. Racimo de mocárabes de uno de los fragmentos depositados en el Museo de León. Fotografía: Archivo de la Comandancia de Obras de Valladolid (abajo izquierda)

- Lám. IV. Fragmento de una techumbre del Palacio Real leonés. Museo de León (abajo derecha) 


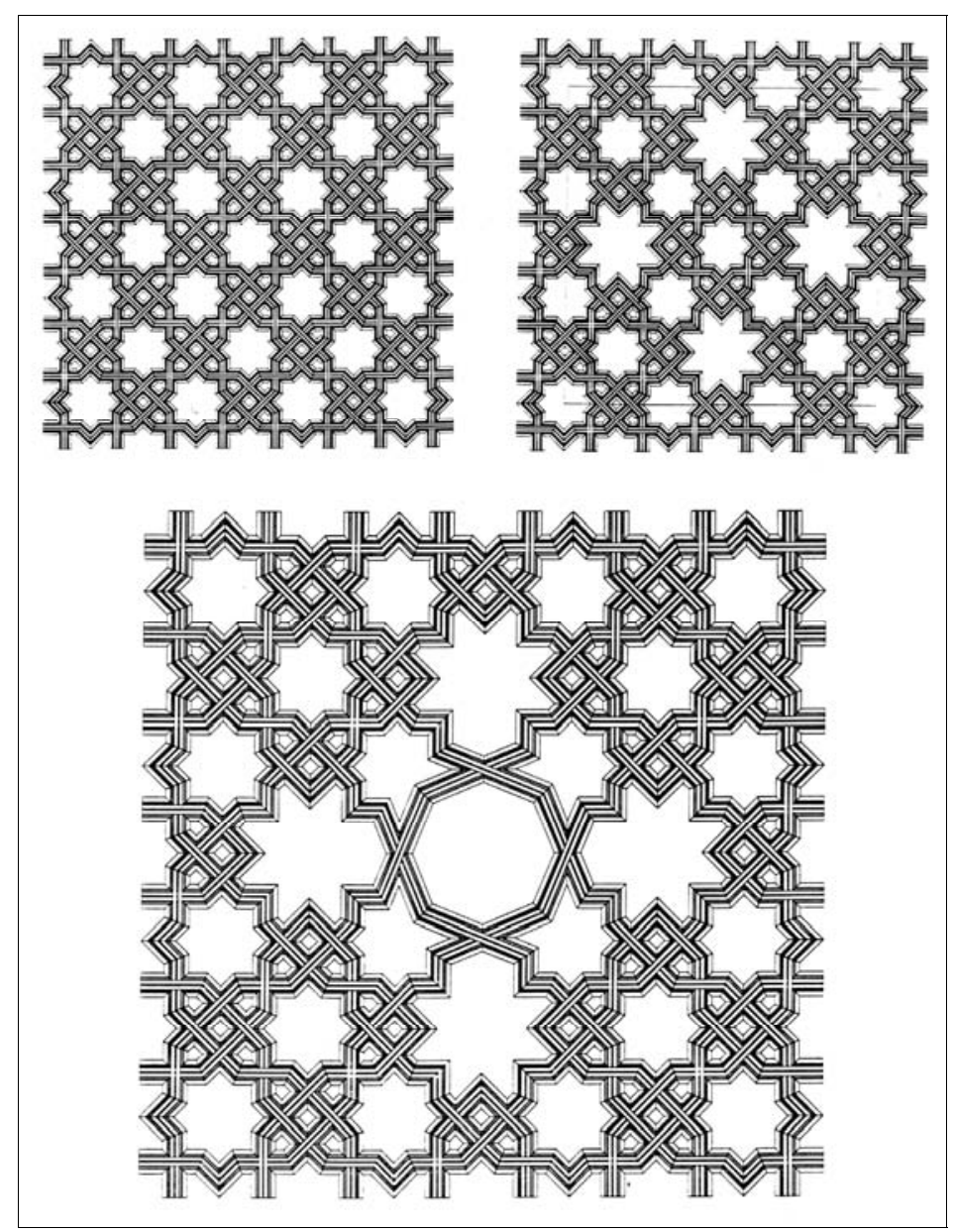

- Fig. I. Procedimiento de variantes y supresiones en el lazo reticular formado por estrellas de ocho puntas y lacillos de cuatro para incorporar el racimo de mocárabes. Dibujo: Agustín Castellanos Miguélez (Centro de Oficios de León). (arriba izquierda)

- Fig. II. Reconstrucción hipotética de uno de los almizates depositados en el museo de León. Dibujo: Agustín Castellanos Miguélez (Centro de Oficios de León).

(abajo centro)

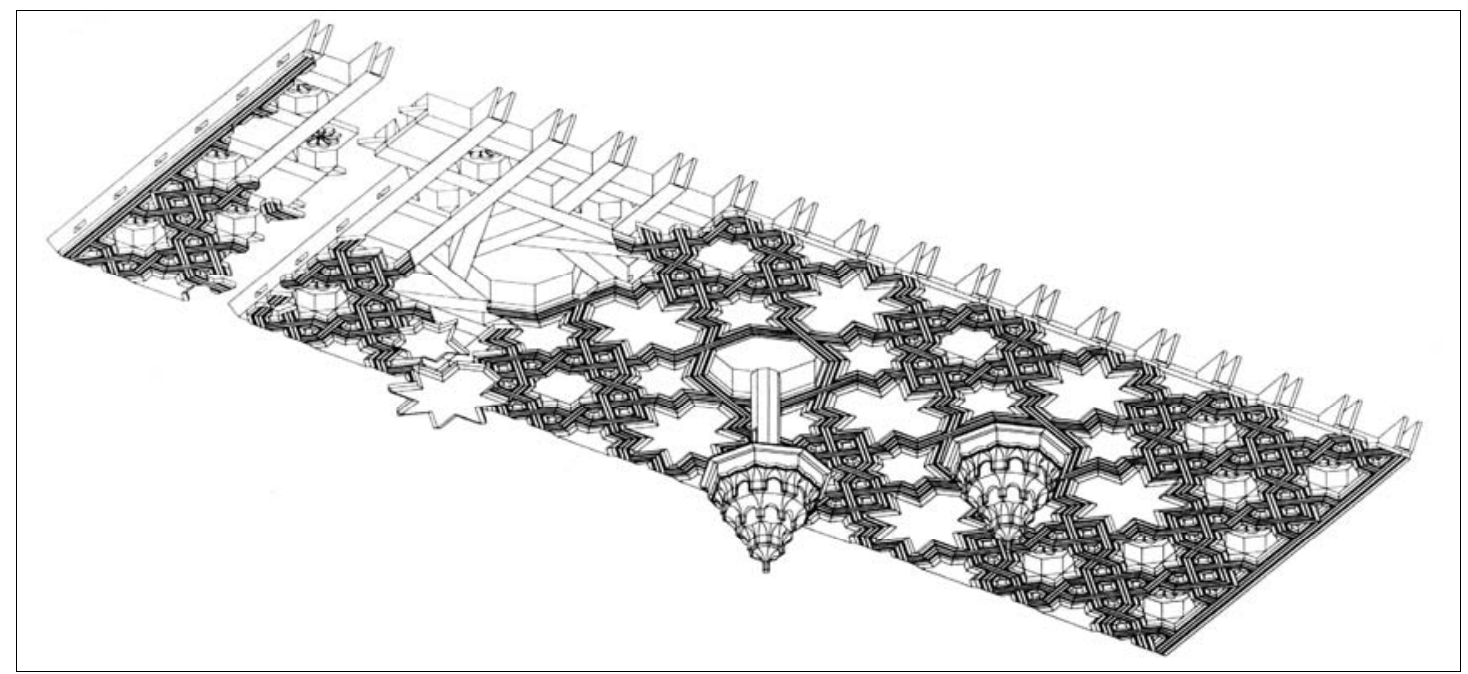




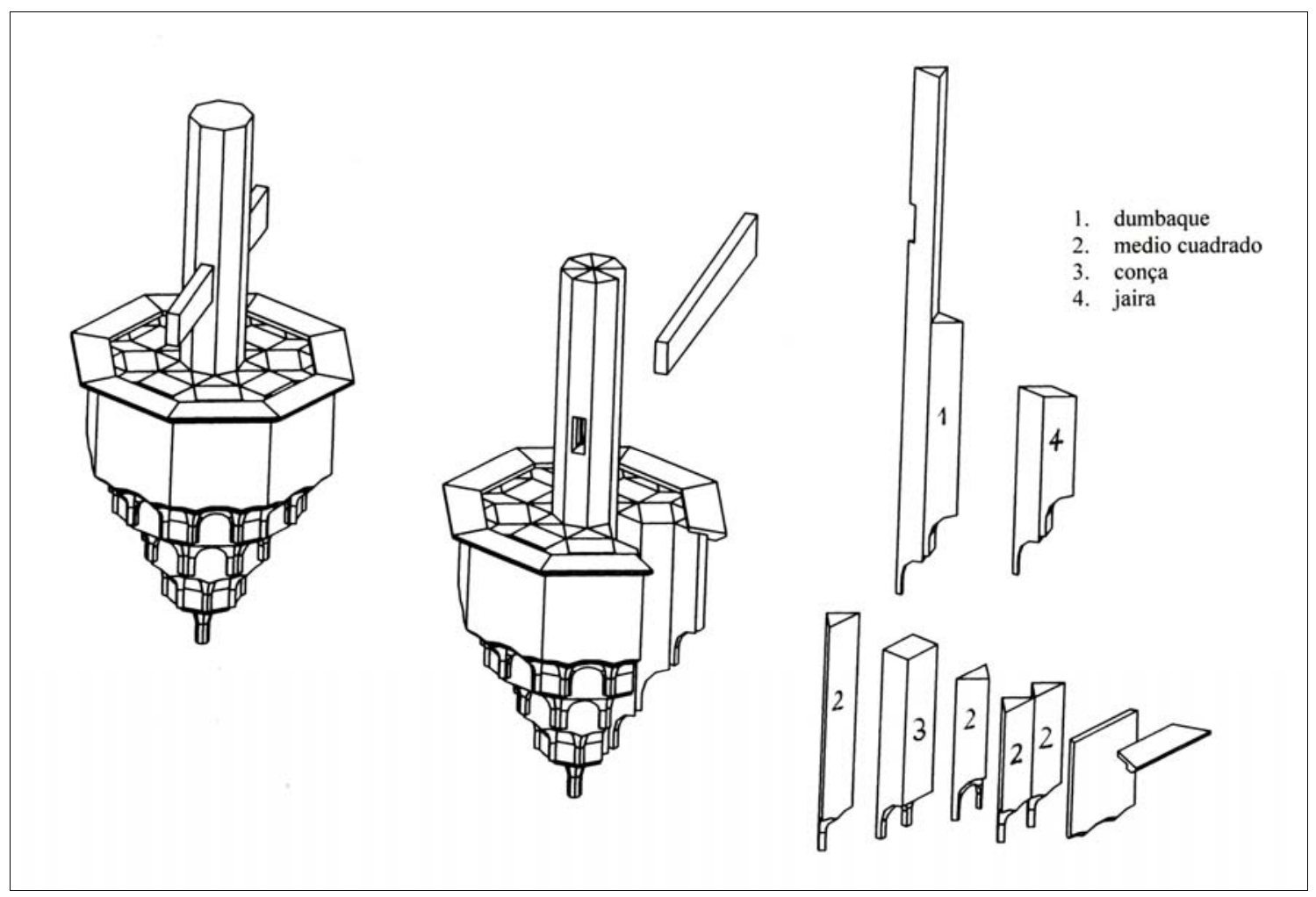

- Fig. III. Configuración del racimo de mocárabes mediante adarajas. Dibujo: Agustín Castellanos Miguélez (Centro de Oficios de León).

(arriba centro) 